\title{
SEA and planning: 'ownership' of strategic environmental assessment by the planners is the key to its effectiveness
}

\author{
Gernot Stoeglehner, A.L. Brown and Lone B. Kørnøv
}

\begin{abstract}
As the field of strategic environmental assessment (SEA) has matured, the focus has moved from the development of legislation, guidelines and methodologies towards improving the effectiveness of SEA. Measuring and of course achieving effectiveness is both complex and challenging. This paper suggests that SEA professionals need to consider 'democratic effectiveness' as well as 'environmental effectiveness' in both 'direct' and 'indirect' outputs. The effectiveness of SEA depends critically on the context within which SEA legislation and guidelines are understood and implemented, and the relationship of the SEA to the planning activity itself. This paper focuses on the influence that planners have in these implementation processes, postulating the hypothesis that these are key players in achieving effectiveness in SEA. Based upon implementation theory and empirical experience, the paper discusses the role of the planners in SEA implementation, concluding that their 'ownership' of SEA is crucial for both democratic and environmental effectiveness.
\end{abstract}

Keywords: strategic environmental assessment, SEA effectiveness, SEA ownership, SEA

integration; implementation theory

Gernot Stoeglehner is at the Institute of Spatial Planning and Rural Development, Department of Spatial, Landscape and Infrastructure Sciences, BOKU-University Vienna, Peter Jordan Str. 82, 1190 Vienna, Austria; Email: gernot.stoeglehner@ boku.ac.at; A.L. Brown is at Urban Research Program, Griffith School of Environment, Griffith University, Brisbane, Australia; Lone B. Kørnøv is at the Department of Development and Planning, Aalborg University, Aalborg, Denmark. concerned with the use of SEA in planning contexts, particularly spatial planning at the regional or local level.

The European Union (EU) considers SEA an important tool for environmental protection and sustainable development (Feldmann and Vanderhaegen, 2001) and released Directive 2001/42/EC on the 'Assessment of the Effects of Certain Plans and Programmes on the Environment' (European Commission, 2001). This is a framework that provides each member state with the opportunity to vary its specific interpretation and implementation. The main elements of SEA in EU practice are the environmental report; consultations with the public, environmental authorities and significantly affected member states; consideration of the SEA results in the decision about the adoption of the plan or programme; an explanatory statement of the decision from an environmental perspective; and monitoring. SEA, according to the EU Directive, has to be applied in all major fields of planning including 'agriculture, forestry, fisheries, energy, industry, 
transport, waste management, water management, telecommunications, tourism, town and country planning or land use' (Art. 3(2a) SEA Directive) for all plans and programmes that meet certain criteria. Outside the EU, SEA is required in various jurisdictions as, for example, in planning EIA for certain types of plan, including urban plans in China (Environmental Impact Assessment Law of the People's Republic of China, 2003); administrative requirements for policy programmes, and plans by Cabinetlevel directive in Canada (Privy Council Office and Canadian Environmental Assessment Agency, 2004); for various planning activities including provincial level cities in Vietnam (Partidário et al., 2008); and spatial planning in South Africa (Department of Environmental Affairs and Tourism (DEAT), 2000).

SEA is now extensively practised. However, empirical research and evaluations of its effectiveness are still limited (Partidario and Fisher, 2004; Sheate et al., 2001; Retief, 2007). In much of the literature critical evaluations of SEA concepts have focused largely on the conduct of SEA, its content and assessment procedures, and the scientific quality of the assessment. There has been too little evaluation of matters that are more central to achieving the underlying objectives of SEA. These include (Nitz and Brown, 2001):

- how well SEA fits plan-making processes;

- acceptance of SEA as a critical tool in plan making;

- the impact of SEA on decision making within these processes; and

- the effect of SEA on outcomes.

The aim of this paper is to extend consideration of SEA effectiveness in plan-making to include planners themselves, and in particular to their 'ownership' of the SEA process. Our thesis is that effectiveness of SEA in planning (and evaluation of that effectiveness) should include assessing the nature, extent and quality of such 'ownership'.

Studies of the implementation and effectiveness of SEA to date provide little understanding of how planners perceive or influence the role of SEA in planning and decision making. We argue that this needs further attention, and suggest that implementation theory can help us to know what to look for and what might be potential barriers. The paper draws from implementation theory and discusses the influence of planners in shaping SEA effectiveness.

Discussion and evaluation of effectiveness of SEA have covered diverse topics, including the measurement of environmental-related change before and after SEA; measurement of changes to the plan due to SEA; measurement of the quality of the environment; asking practitioner opinions on SEA effectiveness (Therivél and Minas, 2002); the interaction between content, processes and outcomes (Owens et al., 2004); the influence of context on effectiveness (Runhaar and Driessen, 2007; Bina, 2008; Hilding-Rydevik and Bjarnadottír, 2007); and ex-post evaluation of SEA (Morrison-Saunders and Arts, 2004; Partidário and Arts, 2005; Partidário and Fischer, 2004). It is not the authors' intention to review this literature, but it is useful, for our purposes, to touch upon it.

SEA effectiveness can be approached through either direct or indirect environmental outputs (Thissen, 2000; Sadler, 2004). The direct outputs relate to the goals of SEA, often including sub-goals such as improving environmental quality and the inclusion of environmental knowledge in decision making. Indirect outputs have to do with 'changes in attitudes towards the environment, improved awareness, changes in institutional arrangements and departmental traditions, etc.' (Retief, 2007: 87). The first approach, the goal model, is a basic approach to organizational effectiveness (Hall, 1980) which defines effectiveness as 'the degree to which [an organization] realizes its goals' (Etzioni, 1964: 8). Because of the diversity of interests and goals within organizations, the goal model has particular difficulties for evaluation of effectiveness in practice. The direct environmental effectiveness of SEA is widely discussed in terms of its impact on the decisionmaking process (Partidário 2000; Retief 2007; Runhaar and Driessen, 2007) and on practitioners. Discussion of the effectiveness of SEA that centres on the quality of the SEA process, the comprehensiveness of the SEA report, or the participatory methods used - that is, 'has a good SEA been conducted' - is a narrower approach to effectiveness, ignoring whether the SEA has contributed to the implementation of an environmentally sound and sustainable planning outcome.

In addition to direct and indirect environmental effectiveness, there is a need to consider an additional model, or dimension, of effectiveness: democratic effectiveness. This is based on experience that, for SEA to make a decisional difference, it needs to be integrated into the planning and decision-making process, and that the political system is a crucial consideration for environmental effectiveness (Kørnøv and Thissen, 2000; Sheate et al., 2001; Nitz and Brown, 2001; Therivél and Minas, 2002). Democratic effectiveness is an important norm in democracy theory, and refers to effectiveness such as when political decision makers make the 'right' decisions and choose the means to fulfil the political environmental objectives; and the administration implements a political decision to perform SEA according to certain legislation and guidelines. These different dimensions of effectiveness are summarised in Table 1.

Evaluating the effectiveness of SEA is challenging. First, SEA is applied in complex, political decision-making processes (Kørnøv and Thissen, 2000; Nitz and Brown, 2001; Partidário and Arts, 2005). Second, assessing effectiveness requires clear SEA objectives, but in practice these can be difficult to 
Table 1. Dimensions of effectiveness

\begin{tabular}{|c|c|c|}
\hline & $\begin{array}{l}\text { Democratic } \\
\text { effectiveness }\end{array}$ & $\begin{array}{l}\text { Environmental } \\
\text { effectiveness }\end{array}$ \\
\hline \multirow[t]{4}{*}{ Direct effectiveness } & \multirow{2}{*}{$\begin{array}{l}\text { Political choice of } \\
\text { means that fulfil } \\
\text { environmental } \\
\text { objectives }\end{array}$} & $\begin{array}{l}\text { Improving } \\
\text { environmental quality }\end{array}$ \\
\hline & & $\begin{array}{l}\text { Inclusion of } \\
\text { environmental }\end{array}$ \\
\hline & \multirow[t]{2}{*}{$\begin{array}{l}\text { SEA implemented } \\
\text { by the } \\
\text { administration as } \\
\text { politically decided }\end{array}$} & $\begin{array}{l}\text { knowledge in } \\
\text { planning and decision } \\
\text { making }\end{array}$ \\
\hline & & $\begin{array}{l}\text { Single- and double- } \\
\text { loop learning }\end{array}$ \\
\hline \multirow[t]{3}{*}{$\begin{array}{l}\text { Indirect } \\
\text { effectiveness }\end{array}$} & $\begin{array}{l}\text { Change in sense of } \\
\text { democracy }\end{array}$ & $\begin{array}{l}\text { Institutional } \\
\text { development }\end{array}$ \\
\hline & \multirow{2}{*}{$\begin{array}{l}\text { Double-loop } \\
\text { learning }\end{array}$} & Double-loop learning \\
\hline & & Changes in attitudes \\
\hline
\end{tabular}

operationalize. If SEA objectives are unclear, one can attempt to assess effectiveness by having input from different actors (politicians, NGOs, administrators, researchers etc.), but this then leads to a third factor that challenges the evaluation of effectiveness: the needs and expectations of different players regarding SEA, which are very likely to be conflicting. It cannot be expected that there will be one universal model of organizational effectiveness (Cameron and Whetten, 1981; Cameron, 1986): it is more likely that one might expect that 'effectiveness involves tradeoffs and management of paradoxes' (Lewin and Minton, 1986: 515). Fourth, 'the chain of cause and effect is unclear or attenuated' (Sadler and Verheem, 1996: 19), which means that it can be difficult to ascertain whether actions other than SEA have had a confounding effect. Fifth, it can be difficult to distinguish between quality and effect in the evaluation of effectiveness. In principle it is a matter of two different things, illustrated by the statement: 'the operation went well, but the patient died'. One example of this is the evaluation of public participation in SEA - is it then quality or effect we are measuring?

This paper discusses the notion of 'ownership' of the SEA by those who conduct, or control, or make decisions about the planning process. Such 'ownership' involves:

\section{It cannot be expected that there will be one universal model of organizational effectiveness: it is more likely that one might expect that 'effectiveness involves tradeoffs and management of paradoxes'}

- the planners who are actually organizing the planning process and elaborating the surveys, analysis and draft plans and programmes - and who, in some regimes, might also conduct the environmental assessment;

- the political decision makers who give democratic legitimacy to the planning processes and who actually have to provide the values and objectives necessary for the planning.

This notion has had little consideration to date, but may play a crucial role as a requisite to achieving SEA effectiveness across its different dimensions.

Consideration of SEA ownership could provide answers to questions such as: How can SEA processes be structured so as to facilitate effective consideration of the environment in plan making? How can planners be provided with incentives to use EA information and results effectively in their plan making? Why might planners either 'own' or 'disown' the ideas and components of SEA? In addition, the contribution SEA could make to planning activities clearly warrants analysis.

\section{Implementation theory and planners}

Implementation theory predicts or explains the implementation process, starting from policy making or policy formation and ending with the effects of implementation. SEA implementation is thus the process of establishing the requirements of SEA, from the formulation of legislation to measuring environmental and democratic effectiveness. The implementation process involves top-down perspectives, bottom-up perspectives and external factors (Mazmanian and Sabatier, 1983). The top-down perspective includes, for example, legal and institutional resources to implement SEA. However, clearly stated objectives and sufficient resources are not necessarily prerequisites strong enough to guarantee successful implementation. The bottom-up perspective highlights this, and includes the commitment of different actors (the public, NGOs, politicians, administrators etc.) and the available management skills (Mazmanian and Sabatier, 1983). Winther (1990, 1994) also considers the top-down and bottom-up perspectives in his integrated framework of implementation. He considers four conditions for implementation (Winther, 1990: 20-21):

- 'the character of the policy formation process prior to the law or decision to be implemented;

- the organizational and interorganizational implementation behaviour;

- street level bureaucratic behaviour; and

- the response by target groups and other changes in society.'

This paper focuses on the street level bureaucrats (SLBs) who, in this framework, are the planners and 
other public administrators. The concept of SLBs was first used by Michael Lipsky in 1980, arguing that 'policy implementation in the end comes down to the people who actually implement it', and suggesting that they too need to be seen as public policy makers (Lipsky, 1980: 8). SLBs include administrators who provide services to protect and uphold the law.

Implementation research works on two assumptions: first, that the most significant problem is that involved actors (i.e. planners) have an incentive to act in a way that hinders realization of the objectives. This has to do with the overload of demands and expectations resulting from new policies, and SLBs' response of developing coping strategies to simplify and/or distort the policy aim (Lipsky, 1980); and second, that the success of implementation depends on the capacity of the actors. The two assumptions refer to respectively the actors' willingness and their capability to put the political decisions into operation. The interaction between willingness and capability is complex, and even though the capacity of organizations and employees may be equal, the result can be very different performance with regard to both scope and quality owing to differing levels of interest and willingness (Winther, 1994).

SEA cannot be integrated by individual planners independently. However, planners exercise judgements in the planning process. They are therefore distinct from other kinds of 'environmental bureaucrat' who have more rule-bounded jobs: the administration of environmental legislation where, for example, specific levels of pollutants are set as standards to be achieved. The implementation literature underlines the vital role of SLBs in shaping policy (Sinclair, 2001; Winther, 1990, 1994; Maupin, 1993; Lipsky, 1980). There is often a discrepancy between the actions of SLBs and stated policy (Lipsky, 1980). Even though there are many different kinds or categories of bureaucrat, Lipsky (1980) concludes that there is a range of common behavioural patterns. We suggest that these patterns are of interest for both SEA researchers and practitioners, and that they can shed light on some of the important issues of SEA implementation and effectiveness. Examples of how the planner plays a vital role in effectiveness are discussed below.

\section{The planner is a sense-maker in SEA implementation}

Several authors have argued that policy implementation involves interpretation, and that the 'meaning' of policies is created in a context by the individual implementers (Geertz, 1973; Yanow, 1996). It can be argued that 'an individual's prior knowledge and belief systems affect how they make sense of policy and how they translate understanding into action' (Spillane et al., 2002: 404). In other words, planners will bring their own knowledge, ideas, values, expectations, agendas and abilities to the implementation of SEA, which may be quite different from those of an SEA practitioner (Vicente and Partidario, 2006). This can vary significantly from the original intentions and policy formulation in SEA legislation.

\section{The planner can (mis) understand SEA as being familiar}

An individual's expectations, based on prior knowledge and experience, influence the expectation and understanding of new ideas (Olsen et al., 1996) and 'new ideas are understood as familiar ones, without sufficient attention to aspects that diverge from the familiar, or are integrated without restructuring of existing knowledge and beliefs, resulting in piecemeal changes in existing practice' (Spillane et al., 2002: 398). So, when planners perceive SEA, it can be interpreted as essentially the same as the planning practice already in place. This may either lead to its rejection or perhaps may result in only minor changes to current planning practice.

\section{The planner may utilize SEA but only in implementation gaps}

SLBs experience gaps between their working situation and the demands put forward through legislation, other rules, the politicians/decision makers, the public, and their own limited resources (Winther, 1994; Lipsky, 1980). These gaps can result in a chronic sense of insufficiency, which they may attempt to minimize through a range of 'mitigating measures'. With regard to planners' implementation of SEA, they can mitigate/limit the implementation gap by, for example, focusing on the programmed and more routine planning activities, leaving little time for the 'unprogrammed' SEA procedures, or emphasizing some parts of the SEA and leaving out others, such as, for example, full consideration of environmental alternatives or other lateral solutions.

\section{The planner can innovate through SEA}

If the planner is not bound by the existence of sensemaking based on existing knowledge and belief systems - does not assume that SEA is essentially the same as the existing planning process, and is not experiencing significant gaps between demands and resources - then there is significant potential for him or her to be an important source of innovation. This situation is possible when input from the SLB (the planner) is included in the design and implementation of SEA into the planning activities.

\section{SEA 'integration' in the planning process}

Planning is a political process (Bechmann, 1981) aimed at decisions about a perceived and desired future, in complex or over-complex systems, with incomplete information (Fürst and Scholles, 2001), and bringing levels of facts and values together 
influenced by actors' contexts, concrete decisionmaking situations (Scharpf, 2000) and power relations (Richardson, 2005). The introduction of SEA requirements to planning increases this complexity. 'Integration' of SEA to the planning process can have many different meanings (Hacking and Guthrie 2008). We focus on two dimensions of 'integration': the integration of SEA in the planning procedures on the one hand, and on the other that of environmental issues with all other issues (economic, social, technical) addressed at all stages of the planning and decision-making process.

An example from Austria which provides a generic model of how SEA can be integrated into a planning process has been described by Stoeglehner (2004), and is depicted in Figure 1. It shows that all elements of the SEA process comply with the phases and steps of a planning process and can therefore be quite integrated, at least on a procedural level. Furthermore, content integration means that environmental issues are elaborated together with other planning issues. This scheme can be applied irrespective of whether the planners also conduct the environmental assessment or whether separate planning and assessment teams collaborate - which is largely a matter of the planning and assessment task. Another example of integration, this time between a City Development Strategy and SEA in Vietnam, has been described by Partidário et al. (2008). The need for SEA procedures to be integrated with plan formulation procedures is supported by many commentators (for example, Fischer et al., 2002), but this must not just be just paper integration, or the equivalent of what might be described as a 'hostile merger' in the corporate world.

Does an integrated SEA planning model support or create ownership? Even in a highly integrated planning and SEA system, such as that in Austria, and described in Figure 1, major concerns are raised by planning practitioners about the effectiveness of SEA. For instance, a senior government official stated that not a single SEA had so far significantly improved the environmental performance of a municipal spatial plan in Austria because of the already high environmental standards of existing spatial planning (pre-SEA requirements) and the nature of the political decision-making processes (Maxian, 2007). Furthermore, a positive cost-benefit advantage from SEA is unlikely because the results are not binding on decision makers (Reichelt, 2007). SEA practice is also challenged because decisions are unlikely to be revised even if the environmental assessment reveals significant negative impacts, with environmental consequences being traded off against other planning aspects (Pistotnig, 2007). This parallels observations about sustainability assessment which highlight the risk that, by content integration, environmental issues may receive less weight than economic (and social) issues (Pope and Grace, 2006; Morrison-Saunders and Therivel, 2006).

The statements reflecting Austrian SEA perceptions, which directly address SEA effectiveness in spatial planning, accord with the discussion in Section 2 above. They can be explained by SLBs' perceptions of SEA as something already mostly covered by the planning process. Limited resources for planning make the SLBs focus on routine activities so as to minimize the implementation gaps between their working situation and the SEA requirements. Therefore, innovation in the planning process that one would expect to be initiated by SEA has not happened, and the added value of SEA is judged by SLBs to be minimal.

In order to realize the potential for true innovation through SEA we suggest that, although integration of SEA and planning is essential, by itself it is insufficient. Ownership is the key to effectiveness, as ownership directly addresses the role of SLB planners as sense-makers in the implementation of SEA.

\section{Enhancing ownership}

Our line of argument is quite simple. We can assume that planners involved in any planning process already 'own' at least most of the elements of that process. In many respects, the formal requirements of SEA can be seen as a relatively recent imposition of (potentially) new elements/emphases in these processes, and for SEA to be effective there must be ownership by the planners of these 'additional' emphases/activities. Our take on the word 'ownership' is perhaps more readily illustrated by its antonym: if planners 'disown' the elements/emphases SEA brings, then they refuse to acknowledge or accept them as their own, repudiate them, deny or refute them, or ignore them. Ownership means that planners have to want, use, and then incorporate these within their planning activity - but by this we do not mean that they must exercise proprietary rights over the SEA. For example, the ownership we suggest is necessary could be achieved equally where separate teams undertake planning and the SEA, or where the same team undertakes both roles.

\section{Elements of ownership}

What, in theory, are these additional elements? This will be quite variable depending on the particular planning activity, the nature and components of the planning methodology, and the existing level of commitment to environmental issues or to consultation in any particular context. We propose

\section{Ownership is the key to effectiveness, as it directly addresses the role of SLB planners}


Planning process

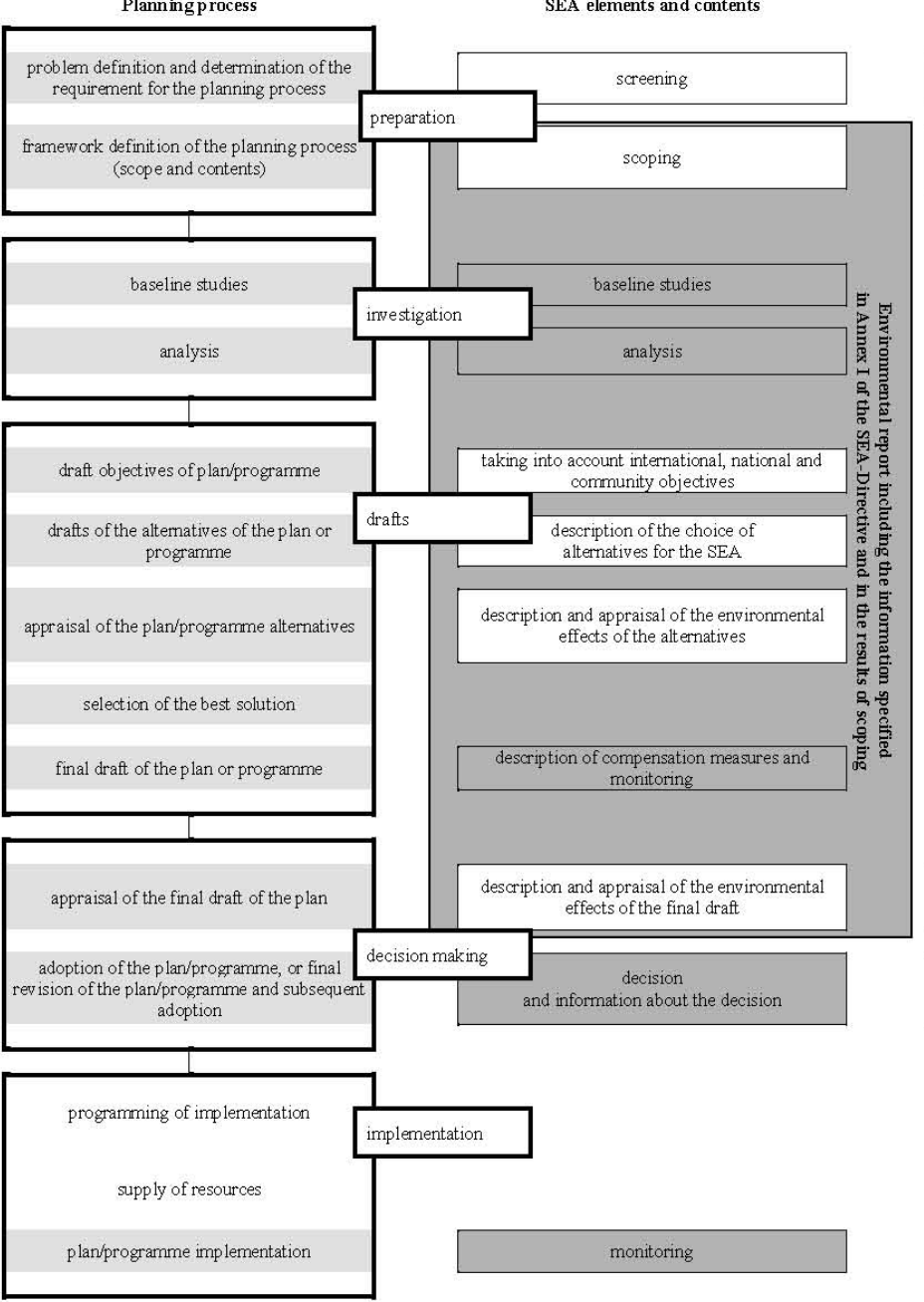

SEA consultations

consultation with envirormental author provision of information to the public

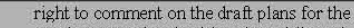

environmental authorities the public and consulted EU-Member States

information about the decision for the environmental authorities, the public and consulted EU-Member States
.

\section{Steps of the planning procedures of the case study \\ Parallels between case study and SEA-process existing}

Figure 1. Planning process with integrated SEA-process of the CDP Hörsching (after Stoeglehner 2004)

the following as a tentative listing of important aspects:

- Ownership of values/concepts:

- Environmental values and objectives;

- Sustainability as a goal;

- Environmentally strategic thinking;

- Ownership of techniques/process:

- Methods for the survey and analysis of environmental assets;

- Establishing environmental objectives and scoping of environmental impacts and opportunities;

- Development of options based on environmental impacts/opportunities;

- Deliberative methods for planning options that include environmental justice and environmental mainstreaming perspectives;

- Putting forward mitigation measures for environmental impacts and search for environmentally friendly alternatives;

- Community input;

- Ownership of outcomes:

- Full environmental effects of options put to decision makers along with other decision criteria;

- Environmental education of and interaction with decision makers re environmental values, objectives, impacts and opportunities;

- Decisions made in the light of environmental effects and opportunities;

- Plan implementation with environmental mitigation.

There needs to be consideration of where in the planning process these would fit, where they overlap with existing planning elements, and impediments to and opportunities for their uptake. 


\section{Ownership of environmental values and sustainability objectives}

Planners and decision makers need to identify the environmental values and sustainability objectives as their own. It is not sufficient that these appear - as they do in many plans - simply as rhetoric. The notions of sustainable development have infiltrated most levels of government, so that there is already likely to be broad-scale acceptance, at the conceptual level, of the need to incorporate sustainability and environmental considerations into plan formulation and decision-making. Ownership of environmental values and sustainability objectives must go much further than mere words, and be manifest throughout the planning process. Values and objectives play a role in each of the following phases of planning, according to Figure 1:

- Preparation phase: formulation of overall environmental goals and inclusion of environmental issues in the scope of the planning process;

- Exploration or investigation phase: survey of environmental assets and analysis of problems and chances related to environmental issues taking environmental values into account;

- Drafting phase: establishing detailed environmental objectives leading to measures for the protection, management and/or development of environmental assets as well as assessing the environmental impacts of the draft plans;

- Decision-making phase: weighting environmental issues at least as much as the other planning issues in the final decision, introducing compensation measures for non-mitigable negative impacts;

- Implementation phase: carrying out measures for protection, management and/or development of environmental assets as well as compensation measures for negative impacts; monitoring of the environmental effects of the plan implementation and taking remedial action if significant negative impacts occur.

How can we increase planners' ownership of environmental values? One answer can be found in theories about collective learning (Innes and Booher, 2000, adapted from Argyris, 1993). If a planning process is interpreted as a collective learning process of a group of planners, decision makers and the involved public, two kinds of learning process can be initiated:

- Single loop learning If negative consequences of a planning proposal can be discovered within the planning process the plan will be adapted without the underlying objectives being questioned. This might lead to mere 'end-of-pipe' adaptation of planning measures or the introduction of compensation measures for negative impacts, but not to a substantial change in values or objectives.
- Double loop learning Double loop learning addresses the level of values so that if, after a single loop, the negative impacts are still not acceptable, the planning objectives are questioned and their feasibility reconsidered. Substantial changes to the planning process can potentially be made that reach back to the preparation phase, so that the planning purpose, framework and overall objectives might be renegotiated.

Standalone SEA has very limited capacity to enhance double loop learning, and hence minimal opportunity to increase ownership of environmental values by planners. SEA as practised often seeks to improve decision making based only on the rational model that better information alone automatically leads to better decisions (Vanderhaegen and Muro, 2005) and that the collection of further information would increase the environmental performance of the plan - predominantly by enabling single loop learning. Integration of environmental values and objectives in the planning process through double loop learning has far more potential if there is ownership of SEA by planners. Such integration has far more relevance for effectiveness than any standalone environmental report (Brown and Therivel, 2000; Partidário, 1996). Contestable, or missing, information is not compensated by further surveys of environmental information, but requires a systematic integration of environment-related values and objectives into the planning process (Dalkmann et al., 2004).

In SEA systems, such as that in the EU, environmental values may be addressed only as environmental objectives that must be documented in the environmental report. The collection of environmental objectives may often be seen as a survey exercise, not a negotiation process regarding environmental values and objectives integral with the planning process. Therefore, as soon as there is scope for discretion on these within the planning process, they can become subsumed under other sets of 'planning' values, disappearing from the preparation of the planning drafts, as the basis of 'environmental' alternatives, and from the information conveyed to the political decision makers for the final decision about the plan or programme to be adopted.

Most existing SEA systems do not promote double loop learning systematically. We argue that ownership of environmental values and objectives can encourage double loop learning, particularly within an integrated SEA/planning process. Because of different social, economic and actor contexts, environmental values and objectives have to be rediscovered and reinvented in each planning process.

Double loop learning requires collaborative streetlevel activity involving planners, decision makers and environmental authorities, and might also involve the public. To enable and enhance these kinds of activities, an unambiguous commitment is 
required, at all relevant political levels, to such environmental values, objectives, appraisal of environmental effects and consideration of environmental issues in all decision making. To implement this activity, different paths of education and awareness raising are required, from education and lifelong learning programmes of planners and assessment professionals, to awareness raising among decision makers, and guidance for integrated planning and assessment processes. It also requires that the role of environmental authorities with regard to planning authorities be redefined - from consultation to collaboration. From a long-term training perspective, we need planning graduates with an understanding of environmental planning and assessment, and environmental graduates with an understanding of planning processes and contents.

\section{Ownership of techniques/processes and outcomes}

Planners need to incorporate the components of SEA methodology fully into their planning methodologies. But unless planners, decision makers and administrators can see that SEA methodology will fit, or readily extend, the way they currently plan and make decisions, and that it will add value, it is unlikely to be embraced, let alone included, and more likely to be met with reluctance, even resistance.

Integration of SEA concepts and processes into planning techniques and processes requires the cooperation of the planners and the decision makers, but it is not a one-way street (Brown and Therivel, 2000). The techniques, processes, time frames and administrative requirements for implementing SEA need to be tailored closely to the particular circumstances of the planning system under consideration (Dalkmann et al., 2004). Proponents of SEA need to develop 'environmental capacity' (Bina, 2008) or the ability to adapt SEA components to existing planning, formulation, and decision-making activities. This will require an understanding of the dynamics, tools and protocols of each planning process, and working to integrate SEA components. SEA proponents will need to understand the stages of planning and policy-making and be able to identify the activities and issues that will be addressed at each stage. In addition, they will need to identify when decisions are made at different stages of the planning process, and by whom, and the appropriate form and content of environmental information that must be available at these decision points. SEA must fit the planning process, not the other way around. Therefore, the adaptation of SEA to planning processes, to the extent that planners and planning decision makers and administrators will start to regard them as their own, will be a critical step for ownership of SEA, and hence for SEA effectiveness.

Building upon implementation theory we make the following points:
- Planners must see and learn how SEA is different from existing planning processes, otherwise there is a risk that they will perceive it as essentially the same as the planning practice already in place, leading either to rejection of SEA approaches or to only minor changes in planning practice.

- Planners need enough resources to avoid implementation gaps between their working situation and the demands of SEA to secure effectiveness and ownership.

- Planners need to be included in the design and implementation of processes so as to incorporate SEA into planning activities.

As a consequence, planners must own the environmental and sustainability dimensions of the outcomes: first within the planning documents (draft plans, approved plan, environmental and other planning reports, explanatory statements of the decision), and ultimately within their implementation over the longer term:

- Planning documents must reflect the environmental considerations and the role environmental issues have played in the decision regarding adoption of the plan;

- In the implementation of the plan there must be an adequate allocation of resources to ensure that action is possible on the environmental issues elaborated and included in the final planning documents. These aspects cover compensation and mitigation measures for identified environmental effects, as well as monitoring and taking remedial action in case of unforeseen environmental impacts.

\section{Conclusions}

Integrating SEA into the planning process is a necessary precondition for effectiveness, but per se is not sufficient. Even when SEA is nominally integrated with planning, there are still two parallel processes effectively taking place: planning and assessment. Without ownership of SEA, SLB planners are unlikely to accept it as a useful tool and are more likely to regard it as an additional bureaucratic activity with little added value.

Increasing the effectiveness of SEA will require the development of links between the planning and assessment processes such that planners profess, and exercise ownership of, SEA values, processes, techniques and outcomes. SLB planners need to be innovative in their integration of SEA in the planning process. Through implementation theory we have highlighted the impediments to effectiveness that can result from the absence of such ownership: that the meaning of policies is created in any context by the individual implementers; that SEA components may currently be misinterpreted by planners as being ostensibly present within current planning activities, 
requiring little or no effective advance in planning practice; or that SEA may be utilized but only to the extent of filling implementation gaps.

The future of SEA effectiveness in the planning process is largely dependent on SLB perceptions and sense-making. If SLB planners believe in the concept and processes of SEA - or in other words, 'own' the SEA - SEA will have the potential to contribute to improved environmental and democratic effectiveness of plans and programmes. If not, it will rarely make much difference to planning outcomes.

\section{References}

Argyris, C 1993. Knowledge for Action: A Guide to Overcoming Barriers to Institutional Change. San Francisco: Jossey Bass.

Bechmann, A 1981. Grundlagen der Planungstheorie und Planungsmethodik. Bern-Stuttgart: UTB für Wissenschaft.

Bina, O 2008. Context and systems: Thinking more broadly about effectiveness in strategic environmental assessment in China. Environmental Management, 42, 717-733.

Brown, A $L$ and $R$ Therivel 2000. Principles to guide the development of SEA methodology. Impact Assessment and Project Appraisal, 18(3), 183-190.

Cameron, K S 1986. Effectiveness as paradox: Consensus and conflict in conceptions of organizational effectiveness. Management Science, 32, 539-553.

Cameron, K S and D A Whetten 1981. Perceptions of organizational effectiveness over organizational life cycles. Administrative Science Quarterly, 26, 525-544.

Dalkmann, H, R J Herrera and D Bongardt 2004. Analytical strategic environmental assessment (ANSEA) developing a new approach to SEA. Environmental Impact Assessment Review, 24, 385-402.

DEAT 2000. Strategic Environmental Assessment (SEA) in South Africa: Guideline Document. Pretoria: Department of Environmental Affairs and Tourism. http://www.adb.org/water/topics/ dams/pdf/sea-sa.pdf [last accessed 23 March 2009]

Etzioni, A 1964. Modern Organizations. NewYork: Prentice-Hall.

European Commission, 2001. Directive 2001/42/EC of the European Parliament and of the Council of 27 June 2001 on the Assessment of the Effects of Certain Plans and Programmes on the Environment.

Feldmann, $L$ and $M$ Vanderhaegen 2001. The SEA Directive and its context UVP-report, 15, 119-122.

Fischer, T B, C Wood and C Jones 2002. Improving the practice of policy, plan and programme environmental assessment. Environment and Planning B, 29(2),159-172.

Fürst, D and F Scholles 2001. Handbuch Theorien + Methoden der Raum- und Umweltplanung. Dortmund: Dortmunder Vertrieb für Bau- und Planungsliteratur.

Geertz, C 1973.The Interpretation of Cultures: Selected Essays. New York: Basic Books.

Hacking, T and P Guthrie 2008. A framework for clarifying the meaning of Triple Bottom-Line, Integrated and Sustainability Assessment. Environmental Impact Assessment Review, 28, 73-89.

Hall R H 1980. Effectiveness theory and organizational effectiveness. Journal of Applied Behavioural Science,16, 536-545.

Hilding-Rydevik, T and HBjarnadottír 2007. Implementation context and implications for formulating the aim and effectiveness of SEA. Environmental Impact Assessment Review, 27, 666-684.

Innes, J and D E Booher 2000. Collaborative Dialogue as a Policy Making Strategy. Institute of Urban and Rural Development, University of California, Berkeley - Working Paper Series, http://repositories.cdlib.org/iurd/wps/WP-2000-05 [last accessed 23 March 2009]

Kørnøv, L and WAH Thissen 2000. Rationality in decision- and policy-making: implications for strategic environmental assessment. Impact Assessment and Project Appraisal, 18(3), 191-200.

Lewin, A Y and JW Minton 1986. Determining organizational effectiveness: Another look, and an agenda for research author(s). Management Science, 32(5), 514-538.

Lipsky, M 1980. Street-Level Bureaucracy: Dilemmas of the
Individual in Public Services. New York: Russell Sage Foundation.

Maupin, J R 1993. Control, efficiency, and the street-level bureaucrat. Journal of Public Administration Research and Theory, 3(3), 335-357.

Maxian, M 2007. Die SUP in der niederösterreichischen Raumordnung. In: Pröbstl U, G Weber, G Stöglehner and A Jiricka, eds.Die Strategische Umweltprüfung (SUP) in der örtlichen Raumplanung - Anspruch und Wirklichkeit, pp. 26-27. Vienna: Eigenverlag.

Mazmanian D A and P A Sabatier 1983. Implementation and Public Policy. Glenview, IL: Scott, Foresman.

Morrison-Saunders, M and J Arts 2004. Assessing Impact: Handbook of EIA and SEA Follow-up, London: Earthscan.

Morrison-Saunders, A and R Therivel 2006. Sustainability integration and assessment. Journal of Environmental Assessment Policy and Management, 8(3), 281-298.

Nitz, T and A L Brown 2001. SEA must Tearn how policy-making works. Journal of Environmental Assessment Policy and Management, 3(3), 329-342.

OECD, 2006. Applying Strategic Environmental Assessment to Development Co-operation. DAC Guidelines and Reference Series, Paris: OECD Publishing.

Olsen, J M, N J Roese and M P Zanna 1996. Expectancies. In: E T Higgens and A W Kruglanski, eds. Social Psychology: Handbook of basic principles, pp. 211-238. New York: Guilford Press.

Owens, S T Rayner and O Bina 2004. New agendas for appraisal: reflections on theory, practice, and research. Environment and Planning, 36, 1943-1959.

Partidário, R M 1996. Strategic environmental assessment: key issues emerging from recent practice. Environmental Impact Assessment Review, 16, 31-55.

Partidário, R M 2000. Elements of an SEA framework - improving the added value of SEA. Environmental Impact Assessment Review, 20, 647-663.

Partidário, R M and J Arts 2005. Exploring the concept of SEA follow-up. Impact Assessment and Project Appraisal, 23(3), 246-257.

Partidário, $M$ and T Fischer 2004. Follow-up in current SEA understanding. In: M Morrison-Saunders and J Arts, eds. Assessing Impact: Handbook of EIA and SEA Follow-up, pp. 224-247. London: Earthscan.

Partidário, R M, M Paddon, M Eggenberger, Dao Mink Chau and Nguyen Van Duyen 2008. Linking strategic environmental assessment (SEA) and city development strategy in Vietnam. Impact Assessment and Project Appraisal, 26(3), 219-227.

People's Republic of China 2003 Environmental Impact Assessment Law of the People's Republic of China.

Pistotnig, L 2007. Umsetzung und Erfahrungen aus der Steiermark - aus persönlicher Sicht. In: Pröbstl U, G Weber, G Stöglehner and A Jiricka, eds.Die Strategische Umweltprüfung (SUP) in der örtlichen Raumplanung - Anspruch und Wirklichkeit, pp. 28-29. Vienna: Eigenverlag.

Pope, J and W Grace 2006. Sustainability assessment in context: Issues of process, policy and governance. Journal of Environmental Assessment Policy and Management, 8(3), 373-398.

Privy Council Office and Canadian Environmental Assessment Agency 2004. Strategic Environmental Assessment: The Cabinet Directive on the Environmental Assessment of Policy, Plan and Program Proposals. Guidelines for Implementing the Cabinet Directive. Ottawa. http://www.ceaa-acee.gc.ca/016/ CEAA-StrategicFinal e.pdf [last accessed 23 March 2009]

Reichelt, W 2007. SUP-Handbuch Kärnten - eine pragmatische Annäherung an die Ziele der SUP-Richtlinie. In: Pröbstl U, G Weber, G Stöglehner and A Jiricka, eds.Die Strategische Umweltprüfung (SUP) in der örtlichen Raumplanung Anspruch und Wirklichkeit, pp. 22-23. Vienna: Eigenverlag.

Retief, $F$ 2007. Effectiveness of strategic environmental assessment (SEA) in South Africa. Journal of Environmental Assessment Policy and Management, 9(1), 83-101.

Richardson, T 2005. Environmental assessment and planning theory: four short stories about power, multiple rationality, and ethics. Environmental Impact Assessment Review, 25, 341-365.

Runhaar H and P Driessen 2007. What makes strategic environmental assessment successful environmental assessment? The role of context in the contribution of SEA to decisionmaking. Impact Assessment and Project Appraisal, 25, 2-14.

Sadler, B 2004. On evaluating the success of EIA and SEA. In Morrison-Saunders $\mathrm{A}$ and $\mathrm{J}$ Arts, eds. Assessing Impact: 
Handbook of EIA and SEA follow-up, Chapter 11. London: Earthscan.

Sadler, B and R Verheem 1996. Strategic Environmental Assessment: Status, Challenges and Future Directions. Report no 53. The Hague: Ministry of Housing, Spatial Planning and the Environment.

Scharpf, F 2000. Interaktionsformen. Akteurszentrierter Institutionalismus in der Politikforschung Opladen: Leske + Budrich.

Sheate, W, S Dagg, J Richardson, R Aschemann, J Palerm and U Steen 2001. SEA and Integration of the Environment into Strategic Decision-making - Vol 1: Final Report to the European Commission. CEC Contract No. B4-3040/99/136634/MAR/B4. London Imperial College Consultants Ltd.

Sinclair, T A P 2001. Implementation theory and practice: Uncovering policy and administration linkages in the 1990s. International Journal of Public Administration, 24(1), 77-94.

Spillane, J P, B J Reiser and T Reimer 2002. Policy implementation and cognition: Reframing and refocusing implementation research. Review of Educational Research, 72(3), 387-431.

Stoeglehner, G 2004. Integrating strategic environmental assessment into community development plans - a case study from Austria. European environment. Journal of European Environmental Policy, 14, $58-72$.

Therivel, R and A L Brown 1999. Methods of strategic environmental assessment. In: Petts J, ed. Handbook of Environmental Impact Assessment, vol 1, pp. 441-464.
Oxford: Blackwell.

Therivel, R and M R Partidário 1996. The Practice of Strategic Environmental Assessment. London: Earthscan.

Therivel, $R$ and $P$ Minas 2002. Ensuring effective sustainability appraisal. Impact Assessment and Project Appraisal, 20(2), 81-91.

Thissen, W A 2000. Criteria for the evaluation of SEA. In: Partidario M and R Clark, eds. Perspectives on Strategic Environmental Assessment, pp. 113-142. Boca Raton: CRC Press.

Vanderhaegen, $M$ and E Muro 2005. Contribution of a European spatial data infrastructure to the effectiveness of EIA and SEA studies. Environmental Impact Assessment Review, 25, 123-142.

Vicente, $\mathrm{G}$ and M R Partidario 2006. Enhancing communication for better environmental decisions. Environmental Impact Assessment Review, 26(8), 696-706.

Winther, S 1990. Integrating Implementation Research. In: Palumbo DJ and D J Calista, eds. Implementation and the Policy Process Opening up the Black Box, pp. 19-38. New York: Greenwood Press.

Winther, S 1994. Implementering og effektivitet (Implementation and Effectiveness), Denmark: Systime.

Yanow, D 1996. How does a policy mean? Interpreting policy and organizational actions. Washington DC: Georgetown University Press. 